\title{
Caracterización del Sistema de Dirección en la Atención Primaria de Salud*
}

\author{
Characterization of the management system in the primary \\ health care
}

\begin{abstract}
Alina María Segredo Pérez
Especialista de I Grado en Medicina General Integral. Máster en Atención Primaria de Salud. Escuela Nacional de Salud Pública. La Habana, Cuba.

De nada sirve el esfuerzo individual, si ese esfuerzo se hace solo, solitario en algún rincón de América ... Y si conocemos el rumbo por donde tenemos que caminar, nos falta solamente conocer la parte diaria del camino a realizar. Y esa parte no se la puede enseñar nadie, esa parte es el camino propio de cada individuo, es lo que todos los días harán, lo que recogerán en su experiencia individual y lo que darán de sí en el ejercicio de su profesión, dedicado al bienestar del pueblo.
\end{abstract}

Che

\section{RESUMEN}

Objetivos Caracterizar las condiciones organizacionales del Sistema de Dirección en la Atención Primaria de Salud.

Métodos El universo de estudio estuvo constituido por los directores de policlínicos de 11 provincias del país para un total de 335, participaron en la investigación 301 para $89,9 \%$. Se aplicaron dos cuestionarios donde se exploraron variables como la edad, sexo, estado civil, tiempo en el cargo, vía de acceso al cargo, condiciones de trabajo para desempeñar la labor, planificación del trabajo, tiempo de superación y su percepción sobre el clima organizacional en que desempeñan sus funciones.

Resultados El grupo de edad de 30 a 35 años fue el más representativo para el $59,5 \%$; el 79,8 \% dirige hace menos de 1 año o entre 1 y 3 años. El 42,1\% accedió al cargo de dirección promovido de otro cargo, el $42,5 \%$ posee equipo de dirección completo. El $81,7 \%$ realizan las reuniones dentro y fuera del horario laboral y el 
$55,2 \%$ refirió que estas se relacionaban con los objetivos de la institución. El 40,5 $\%$ dedica tiempo a la superación, fundamentalmente, a la relacionada con su profesión. La percepción del clima organizacional colocó a la dimensión Motivación en valores inaceptables con cifras entre 2,9 y 1,3 por debajo del límite inferior medio aceptado.

Conclusiones Las condiciones organizacionales del Sistema de Dirección en la Atención Primaria de Salud no son las mejores y es recomendable diseñar un plan de preparación en dirección que responda a las necesidades de cada puesto de dirección en la atención primara de salud donde se involucren los cuadros y sus reservas.

Palabras clave: Sistema de Dirección en la Atención Primaria de Salud, Cuba.

\section{ABSTRACT}

Objectives To characterize the organizational conditions of the Management System in the Primary Health Care.

Methods The universe of study was made up of the managers of the polyclinics of 11 provinces for a total number of 335; the participants in the study amounted to 301 for $89.9 \%$. The questionnaires explored variables such as age, sex, marital status, length of time in performing the managing post, the way of access to the post, working conditions to perform their work, work planning, time devoted to personal upgrading, and perceptions on the organizational environment in which they perform their functions.

Results The 30-35 age group was the most representative for $59,5 \%$ of the sample; $79.8 \%$ of the group hold their managing positions for less than year or for 1-3 years. Of the participants, $42.1 \%$ were promoted from another post to the managing position, $42.5 \%$ have their full management team. Regarding meetings, $81.7 \%$ hold meetings during and out of the working hours whereas $55.2 \%$ reported that these meetings had to do with the institutional objectives. In the study group, 40.55 devoted time to their personal upgrading, mainly to that related to their profession. Perceptions on the organizational environment granted the dimension Motivation scorings of $2.9-1.3$, figures below the allowable average lower limit. Conclusions The organizational conditions of the management system in the primary health care are not the most suitable, so it will be advisable to design a preparation program in management that responds to the requirements of each managing post in the primary health care, where cadres and their replacements are involved.

Key words: Management System in the Primary Health Care, Cuba. 


\section{NTRODUCCI ÓN}

La Organización Mundial de la Salud (OMS.) señala la obligación de los gobiernos de asignar la provisión de recursos para el plan nacional de salud, en su declaración de Alma-Atá en 1978, plantea que la Atención Primaria es la clave para que los pueblos alcancen el grado más alto posible de salud. Define la atención primaria de salud como la asistencia sanitaria esencial basada en métodos y tecnología prácticos, científicamente fundados y socialmente aceptables, puesta al alcance de todos los individuos y familias de la comunidad mediante su plena participación y a un costo que la comunidad y el país puedan soportar, en todas y cada una de las etapas de su desarrollo con un espíritu de autorresponsabilidad y autodeterminación. ${ }^{1}$

En la declaración la OMS plantea que la atención primaria forma parte integrante tanto del sistema nacional de salud, del que constituye la función central y el núcleo principal, como del desarrollo social y económico global de la comunidad.

Representa el primer nivel de contacto de los individuos, la familia y la comunidad con el sistema nacional de salud, llevando lo más cerca posible la atención de salud al lugar donde residen y trabajan las personas, y constituye el primer elemento de un proceso permanente de asistencia sanitaria. ${ }^{1}$

Turabian, en uno de los artículos publicados en los cuadernos de Medicina Familiar y Comunitaria, expone su definición de Atención Primaria de Salud (APS) como el conjunto de actividades y procedimientos organizados, encaminados a preservar y mejorar el estado de salud de la población mediante acciones de promoción, prevención, curación y rehabilitación y evitar que se altere desfavorablemente el medio que lo rodea. $^{2}$

Además plantea que del apoyo a la APS emana un compromiso que da lugar a política, presupuesto y programas donde uno de los indicadores para vigilar el progreso es la disponibilidad de Atención Primaria; muchos países han hecho progresos considerables en la mejora de sus condiciones sanitarias y de desarrollo, pero otros no han mejorado en absoluto. ${ }^{2}$

Tal como han demostrado las experiencias vividas en los diferentes países del mundo, la APS puede adaptarse a distintos niveles de desarrollo y diferentes contextos políticos, sociales y culturales. Dada la creciente dinámica de cambio en el mundo, el panorama actual es distinto, en consecuencia, hoy resulta necesario realizar un análisis de los conceptos teóricos y prácticos de la APS buscando renovación, de manera que pueda reflejar mejor las necesidades de los individuos, las familias y la comunidad.

La renovación de la APS tiene como propósito fundamental revitalizar la capacidad de los países para articular una estrategia coordinada, efectiva y sostenible que pueda dar respuesta a los problemas de salud existente y enfrentar los nuevos retos de salud. La meta de tal propósito es alcanzar un mejoramiento de salud sostenible para todos.

La estrategia de APS está aceptada en los países desarrollados en su intento de cambiar el curso del desarrollo sanitario. Estos tienen dificultades para prestar atención a los aspectos de promoción y prevención por el aumento de la tecnología clínica, los costos y la despersonalización de la atención médica. ${ }^{3}$

En todos los países de América Latina, se ha adoptado la APS como estrategia para lograr la salud para todos. Esto se ha desarrollado sobre un trasfondo de pobreza 
generalizada, creciente desigualdad, exclusión social, inestabilidad política y deterioro del medio ambiente en la mayoría de los países. Un número importante de estos, impulsan hoy procesos de reformas de sus sistemas de salud que, con diversos niveles de desarrollo económico, tienen como empeño común cambiar la forma de organizar y financiar la atención a la salud. ${ }^{3-5}$

Hoy en día existe muy poco consenso en los logros y retos del enfoque de APS para mejorar la salud de la población, pero si se valoran las experiencias exitosas de la APS con su enfoque renovador como piedra angular de las estrategias destinadas a mejorar la salud y la equidad, esta debe ser concebida como un componente esencial de los objetivos de desarrollo económico y social, en su más amplio sentido ${ }^{6-9}$

En Cuba, el Estado asume totalmente la responsabilidad de la atención a la salud de sus ciudadanos. Se concibe la salud como un componente principal de la calidad de vida y como un objetivo estratégico en el desarrollo de la sociedad. ${ }^{10}$

Es por ello, que la política fundamental del Ministerio de Salud Pública cubano, se sustenta en la base de los principios de la APS, donde se debe resolver el $80 \%$ de los problemas, con la participación de la comunidad y todos los sectores económicos y sociales a un costo sostenible. ${ }^{11}$

La APS en Cuba, a partir del fortalecimiento que plantea la nueva estrategia sanitaria cubana, tiene el reto de perfeccionar su sistema de dirección, de modo tal que permita el logro de los objetivos que se propone el sistema para elevar la salud de la población cubana y esto conlleva que se aumente la capacidad de análisis y de dirección a todos los niveles, en sus papeles normativos y de control.

En el proceso de dirección en salud, al igual que en el resto de los sectores, se movilizan recursos humanos, materiales, financieros e instalaciones para prestar servicios a una población determinada, pero tiene un conjunto de características propias devenidas de su objeto de trabajo y de la profesión.

Un sistema de salud es un complejo de una alta significación social, el cual está influido por la dinámica del mercado internacional, el desarrollo de las economías nacionales, el sistema socio-político donde se inscribe y lógicamente, por las posibilidades de acceso tecnológico e informático. ${ }^{12}$

La dirección científica es una influencia con fines determinados sobre el sistema para ponerlo en consonancia con las leyes que le son inherentes. La salud pública socialista como subsistema especializado sólo podrá cumplir su tarea esencial de elevar o mantener el estado de salud de la población cumpliendo con los principios establecidos para la dirección científica de la sociedad. ${ }^{13}$

La organización científica del trabajo es un conjunto de conocimientos científicos y empíricos con cuya aplicación se alcanza el grado máximo de coordinación de los componentes del proceso de trabajo. En Cuba la definición más divulgada es la del Centro Nacional para la Investigación Científica del Trabajo, publicada desde agosto de 1974, que la define como un sistema integrado por un número determinado de elementos que tienen carácter objetivo, derivados del contenido del concepto de trabajo vivo. Entre estos elementos están la división y cooperación, métodos de trabajo, organización y servicios al puesto de trabajo, condiciones, formación, disciplina laboral y organización del trabajo. ${ }^{13}$ 
Según Aldereguía, la organización científica del trabajo es parte del contenido básico de la estrategia para el perfeccionamiento de la dirección científica de la salud. ${ }^{14}$ Este perfeccionamiento en la APS debe partir de un análisis de la estructura y funcionamiento organizacional, existente en un momento dado.

Según plantea Rojo, ${ }^{12}$ la Dirección en Salud es una de las áreas de conocimiento básico que conforman a la Salud Pública como ciencia y se define como aquella disciplina que tiene por finalidad la explicación del comportamiento de la organización y su conducción para la obtención de objetivos predeterminados, consecuentes con una determinada organización, los que se alcanzan con el esfuerzo de los trabajadores, en una interacción humana constante.

En el sector de la salud es muy importante, en los procesos de cambio, tener en cuenta la manera de conducirlos, la forma de actuar de los directivos ante las diferentes situaciones que se le presentan en el quehacer diario, pues en la dirección de los sistemas sociales, donde cada situación requiere de matices diferentes, la solución depende en buena medida de las competencias en dirección que tengan los directivos.

La capacidad directiva se considera como un recurso indispensable para el avance de cualquier sociedad, elemento necesario a desarrollar por los cuadros que como bien expresara el Comandante Ernesto "Che" Guevara de la Serna en "El cuadro columna vertebral de la Revolución, septiembre de 1962:

Un cuadro, es un individuo que ha alcanzado el suficiente desarrollo político como para poder interpretar las grandes directivas emanadas del poder central, hacerlas suyas y transmitirlas como orientación a la masa, percibiendo además las manifestaciones que ésta haga de sus deseos y sus motivaciones más íntimas. Es, además, un individuo con capacidad de análisis propio, lo que le permite tomar las decisiones necesarias y practicar la iniciativa creadora

Es importante tener presente la capacidad del cuadro de compartir la identificación y el análisis de los problemas con los subordinados, por tanto, un directivo en salud que permite la participación en el análisis para la toma de decisiones, está fomentando la dirección participativa como un proceso en el cual los subordinados comparten una cantidad importante de capacidad de decisión con sus superiores.

En el desarrollo organizacional de una institución desempeña un papel decisivo el recurso humano con capacidad directiva; entiéndase por organización a la unidad social coordinada, consciente, compuesta por dos personas o más, que funciona con relativa constancia a efecto de alcanzar una meta o una serie de metas comunes, con el propósito de ayudar a lograr que los objetivos tengan significado y contribuyan a la eficiencia. Este abordaje tiene en cuenta dos elementos esenciales, la estructura y el funcionamiento de la institución. ${ }^{15}$

La estructura organizacional no es la interpretación superficial y estática que reflejan los esquemas de los organigramas, si no, que es un ordenamiento dinámico, cambiante, como un conjunto de interacciones y coordinaciones entre los medios, los procesos y el componente humano de la organización, para asegurarse que este logre sus propósitos sociales. Es decir, que la integren también los elementos organizativos del trabajo. ${ }^{16}$

El funcionamiento de una organización está definido como el conjunto de procesos que le da vida y movimiento. Lo integran múltiples elementos que tienen que ver 
con la manera en que se desarrollan las actividades para poder cumplir con la misión asignada. ${ }^{17}$

La estructura y funcionamiento de una organización son aspectos estrechamente interrelacionados. Esto hace que cada día cobre mayor importancia para la dirección el análisis del Ilamado Clima Organizacional. Este se define como, el conjunto de percepciones de las características relativamente estables de la organización, que influyen en las actividades, el comportamiento de sus miembros, y en el ambiente psicosocial en el que se desenvuelven los trabajadores de una organización determinada. ${ }^{18}$

El Clima Organizacional constituye un instrumento por excelencia para el cambio en busca del logro de una mayor eficiencia organizacional, condición indispensable en el mundo actual, caracterizado por la intensa competencia en el ámbito nacional e internacional. En estos tiempos cambiantes es cada vez más necesario comprender aquello que influye sobre el rendimiento de los individuos en el trabajo. ${ }^{19}$

Desde principios del siglo xix, se ha puesto en evidencia el papel de los componentes físicos y sociales sobre el comportamiento humano. Así es como el clima organizacional determina la forma en que un individuo percibe su trabajo, su rendimiento, su productividad, su satisfacción, entre otros aspectos.

En el mundo de la teoría, se analiza una diversidad de factores que afectan el comportamiento de los individuos en una organización. El comportamiento organizacional de una institución es una ciencia de la conducta aplicada, donde se tiene en cuenta para su análisis la interrelación de varias disciplinas, como la psicología, la sociología, la ciencia política, entre otras. Cada una de estas ciencias utiliza como unidad de análisis al individuo, el grupo y el sistema de dirección. ${ }^{20}$

En salud pública se le da gran importancia a la valoración del clima organizacional en las instituciones porque constituye un elemento esencial en el desarrollo de su estrategia organizacional planificada, posibilitándole al directivo una visión futura de la organización, y como elemento diagnóstico de la realidad cambiante del entorno, lo que permite identificar sus necesidades reales en relación con el futuro deseado, para de esta forma trazar las acciones que deben iniciarse en el presente que permitan alcanzar la visión del futuro diseñado para la institución.

El clima organizacional, que está íntimamente relacionado con la estructura y funcionamiento de la organización, tiene una gran trascendencia en el comportamiento de las personas. Un adecuado clima fomenta el desarrollo de una cultura organizacional establecida sobre la base de necesidades, valores, expectativas, creencias, normas y prácticas compartidos y trasmitidos por los miembros de una institución y que se expresan como conductas o comportamientos compartidos. ${ }^{12}$

Los factores y estructuras del sistema organizacional dan lugar a un determinado clima, en función a las percepciones de los miembros. Este clima resultante induce determinados comportamientos en los individuos. Estos comportamientos inciden en la organización, y por ende, en el clima, por lo que actúa en forma de circuito. ${ }^{21}$

Para comprender la interacción que existe entre los elementos estructurales, su funcionamiento y el clima organizacional que se genera en la institución, es necesario tener en cuenta los siguientes elementos: ${ }^{21}$

- El Clima se refiere a las características del medio ambiente de trabajo. 
- Estas características son percibidas directa o indirectamente por los trabajadores que se desempeñan en ese medio ambiente.

- El Clima tiene repercusiones en el comportamiento laboral.

- El Clima es una variable que media entre los factores del sistema organizacional y el comportamiento individual.

- Estas características de la organización son relativamente permanentes en el tiempo, se diferencian de una organización a otra y de una sección a otra dentro de una misma institución.

- El Clima, junto con las estructuras, las características organizacionales y los individuos que la componen, forman un sistema interdependiente altamente dinámico.

Las percepciones y respuestas que se involucran en el clima organizacional originan una gran variedad de factores que pueden estar influenciados por el liderazgo, las prácticas de dirección, las comunicaciones, relaciones de dependencia, promociones, remuneraciones, entre otros.

En salud cada organización es única y todo grupo humano desarrolla características especiales. La singular cultura de una organización es el producto de todas sus características: sus integrantes, sus éxitos y sus fracasos. Al margen de las normas establecidas cada organización desarrolla una personalidad determinada.

La calidad de la vida laboral de una organización está mediada por el entorno, el ambiente, el aire que se respira en una organización. Los esfuerzos para mejorar la vida laboral constituyen tareas sistemáticas que llevan a cabo las organizaciones para proporcionar a los trabajadores una oportunidad de mejorar sus puestos y su contribución.

Como bien expresara Pérez Maza, ${ }^{22}$ garantizar servicios de calidad ha sido siempre una prioridad del Ministerios de Salud Pública, ya que mediante acciones de optimización y mejoramiento de los servicios que se le brindan a la población se logra una mayor eficiencia, una ventana de opinión sobre el nivel de satisfacción de la población y su contribución a la solución de los problemas identificados; mejora la satisfacción laboral, cuestión que permitirá alcanzar un mayor respeto y confianza de la sociedad, por tanto la calidad no puede ser planteada en términos cognitivos, sino que debe medirse también en términos de respuesta a las necesidades sociales en las que están inmersas las instituciones de salud donde tiene un papel relevante las competencias que poseen los directivos demostradas en su desempeño.

Actuando en consecuencia con estos hallazgos, tanto los directivos como los funcionarios de salud, así como los profesionales de la administración de los recursos humanos, se unen en la necesidad de crear en su organización un clima en el que verdaderamente se trate a las personas como expertos responsables en sus puestos.

Desde el enfoque del desarrollo organizacional, se considera que el hombre tiene aptitudes para la productividad y que estas pueden permanecer inactivas si el ambiente en el que vive y trabaja le es restringido, hostil y le impide tanto el crecimiento como el desarrollo de sus potencialidades.

Para el logro de un ambiente organizacional adecuado, favorable y constructivo es importante fomentar en los colectivos de trabajo el elemento educativo encaminado a cambiar actitudes, desarrollar habilidades, valores y comportamientos; con el objetivo de lograr la participación comprometida de todos los trabajadores en la 
transformación del sistema de salud que se traduzca en mejoramiento continuo del estado de salud de la población y se exprese en las transformaciones favorables de los indicadores con una mayor calidad de vida de los individuos, la familia y la comunidad.

El Sistema Nacional de Salud, en Cuba, en los momentos actuales, desarrolla un proceso de perfeccionamiento donde la atención primaria constituye el eje conductor de la estrategia sanitaria cubana. Esta desempeña un importante papel en el mantenimiento o mejoramiento del estado de salud de la población; para lograr el fortalecimiento a este nivel se hace necesario realizar los cambios precisos y garantizar la estabilidad en los cuadros de dirección que le den continuidad al proceso. Dentro de las tareas definidas en las estrategias organizacionales se encuentra garantizar la mejora continua de los servicios vitales en los policlínicos.

Estos elementos son los que en la actualidad, por su importancia, hacen que se lleve a cabo este tipo de investigación, la cual tiene gran relevancia para el Ministerio de Salud Pública, muy en especial para la Dirección Nacional de Cuadros y de APS; teniendo en cuenta que esta última centra su trabajo en incrementar la calidad de vida de los individuos, la familia y la comunidad. Contribuir al desarrollo de los sistemas y servicios de salud fue la motivación para realizar este estudio, cuyos objetivos son: 1 . Caracterizar elementos relacionados con la estructura y funcionamiento del puesto de trabajo de los directores de policlínico y 2 . Identificar su percepción en relación con el clima organizacional en su puesto de trabajo.

\section{CONTROL SEMÁNTICO}

\section{Liderazgo}

Capacidad de asumir la responsabilidad de conducir a otros al efectivo logro de sus fines personales o colectivos, influyendo en ellos, compartiendo valores, visión, ejemplaridad, creatividad, espíritu de iniciativa y de servicio, comunicación eficaz, y trabajo en equipo y valores éticos. ${ }^{23}$

\section{Motivación}

Voluntad de realizar altos niveles de esfuerzo para alcanzar las metas organizacionales, condicionada por la capacidad del esfuerzo para satisfacer alguna necesidad individual o colectiva ${ }^{23}$

\section{Reciprocidad}

Relación de dar y recibir mutuamente entre el individuo y la organización. ${ }^{24}$

\section{Participación}

Contar con las personas, compartir con ellas decisiones y tareas, abrirles espacios para el cumplimiento de sus derechos y deberes sociales y políticos, brindarles la posibilidad de ser parte activa en la gestión y beneficios de una tarea y ofrecerles la posibilidad de opinar con libertad. ${ }^{23}$ 


\section{MÉTODOS}

\section{Tipo de estudio}

Se desarrolló una investigación descriptiva de corte transversal para caracterizar las condiciones organizacionales del Sistema de Dirección en la Atención Primaria de Salud, específicamente los directores de las áreas de salud, en 13 provincias del país.

\section{Universo y muestra}

El universo de esta investigación estuvo constituido por los directores de áreas de salud de 13 provincias del país en el año 2003.

\section{Metódica}

Para dar cumplimiento a los objetivos propuestos en esta investigación se estudiaron las siguientes variables:

Objetivo 1. Caracterizar elementos relacionados con la estructura y funcionamiento del puesto de trabajo, entre ellos:

- Edad, sexo, y estado civil.

- Tiempo en el cargo.

- Vía de acceso al cargo.

- Condiciones de trabajo para desempeñar la labor.

- Planificación del puesto de trabajo.

- Planificación del tiempo de descanso.

- Tiempo de superación.

- Atención a la Salud.

Objetivo 2. Identificar la percepción del personal dirigente sobre el clima organizacional. Para ello se exploraron las siguientes dimensiones:

\section{Liderazgo}

- Dirección.

- Estímulo a la excelencia.

- Estimulo al trabajo en equipo.

- Solución de conflictos.

\section{Motivación}

- Realización personal.

- Reconocimiento a la aportación.

- Responsabilidad.

- Adecuación a las condiciones de trabajo.

\section{Reciprocidad}

- Aplicación del trabajo.

- Cuidado de bienes de la institución.

- Retribución.

- Equidad. 


\section{Participación}

- Compromiso con la productividad.

- Compatibilización de intereses.

- Intercambio de la información.

- Estar involucrado en el cambio.

\section{Técnicas y procedimientos}

De la recolección de datos. Para definir los criterios a considerar para la evaluación de la estructura y funcionamiento de la organización donde los directores de área de salud desarrollan su labor se aplicó una guía de entrevista tomada del trabajo que realizó en Ciudad de la Habana en 1997 Presno Labrador, ${ }^{24}$ (anexo1).

Para identificar la percepción en relación al clima organizacional se utilizó una prueba proyectiva ya aplicada en otros estudios y en la investigación que se efectuó en Ciudad de la Habana en el año $1997^{24}$ y se siguió la metodología que los autores proponen para estos casos (anexo 2).

Ambos instrumentos fueron aplicados en los meses de agosto a diciembre del año 2003 por un grupo colaboradores de la investigación, donde todas las provincias objeto de estudio estaban representadas.

Del procesamiento y análisis. Una vez obtenida la información se creó la correspondiente base de datos. La información obtenida de la aplicación del anexo 2 , se clasificó y agrupó por categorías según instrucciones. Los resultados se expresaron en valores promedios y porcentajes.

\section{Principios éticos}

Se obtuvo la autorización de los directores provinciales y municipales de salud para realizar este estudio. Todos los directores de policlínicos que participaron expresaron su conformidad para ello pues de esta forma contribuían al mejoramiento de su organización.

\section{RESULTADOS Y DISCUSIÓN}

En el estudio que se realizó a los directores de áreas de salud del país, de 13 provincias a investigar, participaron 11 de ellas, no se contó con la información de las provincias de Santiago de Cuba y Ciego de Ávila, por no entrar en tiempo al cierre del procesamiento de los datos. El universo de estudio de estas 11 provincias era de 335 directores de áreas donde sólo participaron en la investigación 301 para el $89,9 \%$.

El sexo y la edad son dos de las características demográficas a indagar en este tipo de estudio, pues permite hacer una descripción de la fuerza laboral en el sector si se tiene en cuenta que Cuba es uno de los pocos países del continente donde un elevado porcentaje de los trabajadores en el sector de la salud son mujeres y por ende en consonancia con ello, se cuenta con su presencia en responsabilidades de dirección, políticas o administrativas. ${ }^{25,26}$ 
De forma general, en la distribución de los directores de áreas de salud en cuanto sexo y edad se pudo comprobar (tabla1), que del total de 301 directores de policlínico encuestados $58,8 \%$ son del sexo masculino y $41,2 \%$ del femeninos. Se destacan estos valores en el grupo de edades de 30 a 35 años con 179 personas, donde $62,7 \%$ son masculinos y $54,8 \%$ femeninos. Mostraron valores muy bajos los grupos de menos de 30 años y el de 41 a 59 años con 6,6 \% y 5,7\%, respectivamente. El predominio del grupo de edad de 30 a 35 años está en correspondencia con que los directores en el nivel de policlínico son profesionales del plan del Médico y Enfermera de la Familia, programa que cuenta con 20 años de iniciado.

Tabla 1. Distribución de Directores de Áreas de Salud según sexo y edad 2003

\begin{tabular}{|l|c|c|c|c|c|c|}
\hline \multirow{2}{*}{ Grupo de Edades } & \multicolumn{2}{c|}{$\begin{array}{c}\text { Mujeres } \\
n=124\end{array}$} & \multicolumn{2}{c|}{$\begin{array}{c}\text { Hombres } \\
n=177\end{array}$} & \multicolumn{2}{c|}{$n=301$} \\
\cline { 2 - 7 } & No. & $\%$ & No. & $\%$ & No. & $\%$ \\
\hline > 30 años & 9 & 7,3 & 1 & 6,2 & 20 & 6,6 \\
\hline $30-35$ años & 68 & 54,8 & 111 & 62,7 & 179 & 59,5 \\
\hline $36-40$ años & 37 & 29,8 & 48 & 27,1 & 85 & 28,2 \\
\hline $41-59$ años & 10 & 8,1 & 7 & 4,0 & 17 & 5,7 \\
\hline
\end{tabular}

Un estudio realizado en Ciudad de la Habana,24 encuentra en su muestra, a diferencia de los resultados de esta investigación, predominio del sexo femenino, pero según grupos de edades encontramos resultados similares.

En relación con el tiempo que llevan desempeñado sus funciones los directores de áreas de salud en el país (tabla 2), el 79,8 \% de ellos dirigen hace menos de 1 año o entre 1 y 3 años, y el 20,2 \% hace más de 5 años.

Tabla 2. Distribución de Directores de Áreas de Salud según tiempo en el cargo y sexo. 2003

\begin{tabular}{|l|c|c|c|c|c|c|}
\hline \multirow{2}{*}{ Tiempo en el cargo } & \multicolumn{2}{|c|}{$\begin{array}{c}\text { Mujeres } \\
n=124\end{array}$} & \multicolumn{2}{c|}{$\begin{array}{c}\text { Hombres } \\
n=177\end{array}$} & \multicolumn{2}{c|}{$\begin{array}{c}\text { Total } \\
n=301\end{array}$} \\
\cline { 2 - 8 } & No. & $\%$ & No. & $\%$ & No. & $\%$ \\
\hline$>1$ año & 46 & 37,1 & 55 & 31,1 & 101 & 33,6 \\
\hline $1-3$ años & 51 & 41,1 & 88 & 49,7 & 139 & 46,2 \\
\hline $4-5$ años & 17 & 13,7 & 19 & 10,7 & 36 & 11,9 \\
\hline+ de 5 años & 10 & 8,1 & 15 & 8,5 & 25 & 8,3 \\
\hline
\end{tabular}

Cuando se hace la comparación por sexos, estos se comportan entre rangos similares para ambos, por lo que no se pone de manifiesto la fuerza de los prejuicios acerca de la inferioridad femenina, que en el mundo laboral es muy fuerte, esto se debe a una política que se ha llevado desde los primeros años de la Revolución, lo que ha permitido escalar peldaños cada vez más altos en el ascenso social a las mujeres, al fomentar la selección y ascenso de estas en niveles de adopción de decisiones en la dirección del país (tabla 2). 
En los resultado alcanzados en esta investigación, predominó de forma general, la categoría de casado con el $68,8 \%$, de igual forma prevaleció esta categoría en ambos sexos con el $62,1 \%$ en las mujeres y el $73,5 \%$ en los hombres, esto se manifestó asimismo en todas las provincias estudiadas (tabla 3 ).

Tabla 3. Distribución de Directores de Áreas de Salud según estado civil y sexo. 2003

\begin{tabular}{|l|c|c|c|c|c|c|}
\hline \multirow{2}{*}{ Estado civil } & \multicolumn{2}{|c|}{$\begin{array}{c}\text { Mujeres } \\
n=124\end{array}$} & \multicolumn{2}{c|}{$\begin{array}{c}\text { Hombres } \\
n=177\end{array}$} & \multicolumn{2}{c|}{$\begin{array}{c}\text { Total } \\
n=301\end{array}$} \\
\cline { 2 - 8 } & No. & $\%$ & No. & $\%$ & No. & $\%$ \\
\hline Casado & 77 & 62,1 & 130 & 73,5 & 207 & 68,8 \\
\hline Soltero & 12 & 9,7 & 8 & 4,5 & 20 & 6,6 \\
\hline Divorciado & 24 & 19,4 & 9 & 5,1 & 33 & 11,0 \\
\hline Unión consensual & 11 & 8,8 & 29 & 16,4 & 40 & 13,3 \\
\hline Viudo & - & - & 1 & 0,5 & 1 & 0,3 \\
\hline
\end{tabular}

Al analizar el número de hijos que tienen los directores de área, se encuentra, como puede apreciarse en la tabla 4, que el $82,7 \%$ poseen entre uno o dos hijos, similar para ambos sexos. Dentro de los que refieren no tener hijos sólo está el 13 $\%$ en hombres y el $11,3 \%$ en las mujeres, esto se corresponde precisamente con el mayor grupo de edad, que en el estudio está representado entre los 30-35 años para ambos sexos, donde la función reproductiva es activa y guarda relación con el predominio del estado civil, casados como apreciamos anteriormente, esto se comportó de similar manera en todas las provincias (tabla 4).

Tabla 4. Distribución de Directores de Áreas de Salud según cantidad de hijos y sexo. 2003

\begin{tabular}{|l|c|c|c|c|c|c|}
\hline \multirow{2}{*}{ Número de hijos } & \multicolumn{2}{|c|}{$\begin{array}{c}\text { Mujeres } \\
n=124\end{array}$} & \multicolumn{2}{c|}{$\begin{array}{c}\text { Hombres } \\
n=177\end{array}$} & \multicolumn{2}{c|}{$\begin{array}{c}\text { Total } \\
n=301\end{array}$} \\
\cline { 2 - 7 } & No. & $\%$ & No. & $\%$ & No. & $\%$ \\
\hline 1 & 62 & 50,0 & 65 & 36,7 & 127 & 42,2 \\
\hline 2 & 44 & 35,5 & 78 & 44,1 & 122 & 40,5 \\
\hline 3 ó más & 4 & 3,2 & 11 & 6,2 & 15 & 5,0 \\
\hline No tienen hijos & 14 & 11,3 & 23 & 13,0 & 37 & 12,3 \\
\hline
\end{tabular}

Dentro de las razones que pueden estar justificando este comportamiento está el desarrollo socio-cultural alcanzado en el país, el que se asemeja cada vez más al de países desarrollados, en ellos, los problemas que afectan a la madre trabajadora no se alejan mucho de la realidad cubana. En esta investigación, son mujeres trabajadoras, profesionales y dirigentes lo que explica por sí solo este comportamiento. ${ }^{24,27}$

La vía de acceso al cargo de dirección que ocupan en la actualidad, se exploró y se obtuvo que el mayor porcentaje lo representa ser promovido de otro cargo $(42,1$ $\%$ ) seguido de proceder de atención directa a la población al estar incluido en la reserva de cuadros, se puede observar como la política de cuadro en el país ha 
mejorado, aunque aún es insuficiente para dar respuesta a los requerimientos actuales de la estrategia sanitaria cubana. ${ }^{28}$

Al compararlo con el estudio realizado en Ciudad de la Habana, este es uno de los aspectos que se encuentra deficiente pues un alto porcentaje de las mujeres directoras de áreas al acceder al cargo de dirección no estaban incluidas en la reserva de cuadros $(43,5 \%) .{ }^{24}$ Los mejores resultados por provincias se obtuvieron en La Habana, Cienfuegos, Sancti Spiritus y Holguín, en ellas de forma general predominaron las mujeres que accedieron al cargo provenientes de la atención directa de la población, por estar incluidas en la reserva de cuadros, pero a pesar de esta situación expresaron que no se sentían preparados para asumir la responsabilidad, por lo que pudiera interpretarse que el plan de desarrollo individual con las reservas no se efectúa debidamente (tabla 5 ).

Tabla 5. Distribución de Directores de Áreas de Salud según acceso al cargo y sexo. 2003

\begin{tabular}{|l|c|c|c|c|c|c|}
\hline \multirow{2}{*}{ Acceso al cargo } & \multicolumn{2}{|c|}{$\begin{array}{c}\text { Mujeres } \\
\mathrm{n}=124\end{array}$} & \multicolumn{2}{|c|}{$\begin{array}{c}\text { Hombres } \\
\mathrm{n}=177\end{array}$} & \multicolumn{2}{|c|}{$\begin{array}{c}\text { Total } \\
\mathrm{n}=301\end{array}$} \\
\cline { 2 - 7 } & No. & $\%$ & No. & $\%$ & No. & $\%$ \\
\hline $\begin{array}{l}\text { Atención Directa a la..Poblacción incluido en la reserva de } \\
\text { cuadros }\end{array}$ & 50 & 40,3 & 57 & 32,2 & 107 & 35,6 \\
\hline $\begin{array}{l}\text { Atención Directa a la..Poblacción no incluido en la reserva } \\
\text { de cuadros }\end{array}$ & 20 & 16,1 & 47 & 26,6 & 67 & 22,3 \\
\hline Promovido de otro cargo & 54 & 43,6 & 73 & 41,2 & 127 & 42,1 \\
\hline
\end{tabular}

Los directores de policlínico en el país como puede verse en la tabla 6 , disponen en su gran mayoría de secretaria $(72,8 \%)$ y local adecuado para trabajar $(67,1 \%)$, lo que se manifiesta en más del $60 \%$, tanto en hombres como en mujeres; pero llama la atención que más de la mitad de este personal no cuenta con equipo de dirección completo para el cumplimiento de sus funciones, lo que podría aumentar su carga de trabajo y limitarle su desempeño. Poseer el $42,5 \%$ de los equipos de dirección completo para los directores, resulta insuficiente, mucho más si se tiene en cuenta que el fortalecimiento de la APS es la primera estrategia priorizada por el MINSAP. Entre las provincias más criticas están: Cienfuegos (4,5\%), La Habana $(15,5 \%)$ y Holguín $(28,9 \%)$, el resto de las provincias tienen más del $50 \%$ de sus equipos completos.

Tabla 6. Distribución de Directores de Áreas de Salud según recursos de que disponen y sexo. 2003.

\begin{tabular}{|l|c|c|c|c|c|c|}
\hline \multirow{2}{*}{ Recursos } & \multicolumn{2}{|c|}{$\begin{array}{c}\text { Mujeres } \\
n=124\end{array}$} & \multicolumn{2}{c|}{$\begin{array}{c}\text { Hombres } \\
n=177\end{array}$} & \multicolumn{2}{c|}{$\begin{array}{c}\text { Total } \\
n=301\end{array}$} \\
\cline { 2 - 7 } & No. & $\%$ & No. & $\%$ & No. & 9 \\
\hline Local adecuado & 90 & 72,6 & 112 & 63,3 & 202 & 67,1 \\
\hline Secretaria & 97 & 78,2 & 122 & 68,9 & 219 & 72,8 \\
\hline Equipo de dirección completo & 55 & 44,4 & 73 & 41,2 & 128 & 42,5 \\
\hline Asesores & 9 & 7,3 & 19 & 10,7 & 28 & 9,3 \\
\hline Otras & 20 & 16,1 & 26 & 14,7 & 46 & 15,3 \\
\hline
\end{tabular}


Cuando se analizó el tiempo dedicado a las reuniones, el 81,7 \% de los directores expresaron que estas se realizan dentro y fuera del horario laboral como se puede observar en la tabla 7. Según refieren los directores, estas actividades comienzan dentro del horario laboral pero generalmente se extienden y terminan entre una a dos horas fuera de la jornada de trabajo, es de destacar que en la provincia de Cienfuegos esta situación se comportó de forma diferente pues refirieron que más del $70 \%$ de estas reuniones de trabajo se realizan fuera del horario laboral.

Tabla 7. Distribución de Directores de Áreas de Salud según horario de reunión y sexo. 2003

\begin{tabular}{|l|c|c|c|c|c|c|}
\hline \multirow{2}{*}{ Horario de reuniones } & \multicolumn{2}{|c|}{$\begin{array}{c}\text { Mujeres } \\
n=124\end{array}$} & \multicolumn{2}{c|}{$\begin{array}{c}\text { Hombres } \\
n=177\end{array}$} & \multicolumn{2}{c|}{$\begin{array}{c}\text { Total } \\
n=301\end{array}$} \\
\cline { 2 - 8 } & No. & 96 & No. & $\%$ & No. & 96 \\
\hline Dentro & 15 & 12,1 & 20 & 11,3 & 35 & 11,6 \\
\hline Fuera & 6 & 4,8 & 14 & 7,9 & 20 & 6,7 \\
\hline Dentro y fuera & 103 & 83,1 & 143 & 80,8 & 246 & 81,7 \\
\hline
\end{tabular}

Al analizar esta situación, se precisó que existe correspondencia con los resultados de la investigación desarrollada por un equipo de investigadores en la Escuela Nacional de Salud Pública (ENSAP) ${ }^{29}$ donde se encuentra que los directores de policlínico, en relación con la distribución de su fondo de tiempo laboral, del total de actividades, 31 como promedio son reuniones a las cuales dedican $200 \mathrm{~h}$ que es más del $60 \%$ del tiempo de trabajo percibido. Plantea la investigación citada arriba que los directores como promedio utilizan $6 \mathrm{~h}$ y 45 min en cada reunión que participan. ${ }^{29}$

En esta investigación, es interesante destacar que de las reuniones que se efectúan, el $55 \%$ aproximadamente de los directivos plantearon que la mayoría de ellas se relacionaban directamente con los objetivos de su institución y sólo el 16,9 $\%$ manifestó que todas se relacionaban con estos objetivos. El $30 \%$ aproximadamente de estas reuniones no se corresponde directamente con los objetivos de la institución, comportándose de forma similar en todas las provincias objeto de estudio (tabla 8).

Tabla 8. Distribución de Directores de Áreas de Salud según cumplimiento de los objetivos de la reunión y sexo. 2003

\begin{tabular}{|l|c|c|c|c|c|c|}
\hline \multirow{2}{*}{$\begin{array}{l}\text { Objetivos de } \\
\text { la reunión }\end{array}$} & \multicolumn{2}{|c|}{$\begin{array}{c}\text { Mujeres } \\
\mathrm{n}=124\end{array}$} & \multicolumn{2}{c|}{$\begin{array}{c}\text { Hombres } \\
\mathrm{n}=177\end{array}$} & \multicolumn{2}{c|}{$\begin{array}{c}\text { Total } \\
n=301\end{array}$} \\
\cline { 2 - 8 } & No. & $\%$ & No. & 9 & No. & $\%$ \\
\hline Todas & 17 & 13,7 & 34 & 19,2 & 51 & 16,9 \\
\hline La mayoría & 69 & 55,7 & 97 & 54,8 & 166 & 55,2 \\
\hline Algunas & 36 & 29,0 & 45 & 25,4 & 81 & 26,9 \\
\hline Ninguna & 2 & 1,6 & 1 & 0,6 & 3 & 1,0 \\
\hline
\end{tabular}

En la investigación realizada por la ENSAP, se plantea que los directores de policlínico utilizan el $44,6 \%$ del tiempo invertido en reuniones que no se corresponden directamente con sus objetivos de trabajo, por lo que sólo pueden dedicar el $40 \%$ de su tiempo de trabajo a las actividades de alto impacto 
estratégico y alto valor agregado, muy por debajo de lo que plantea la literatura, que coloca el estándar entre el 75 y el $85 \%$. Esto también se aprecia en otros estudios revisados. Esta situación hace pensar en la necesidad de realizar un análisis de los objetivos de estas reuniones, para que respondan a los intereses de las áreas de salud y del Sistema Nacional de Salud. ${ }^{29,30}$

La posibilidad de este personal dirigente de disponer de un horario para alimentarse en una semana laboral todos lo días es pobre $(31,6 \%)$, de manera general las mujeres cuentan con menos tiempo que los hombres (tabla 9). Esta situación de forma particular por provincias se expresó de igual forma, esto puede ser debido a la no existencia de comedores para la alimentación a nivel de los policlínicos y podría influir además la falta de tiempo debido a las dificultades con el completamiento del equipo de trabajo y el exceso de reuniones que se extienden al horario no laboral. Este aspecto se debe analizar ya que garantizar una adecuada atención al hombre es un elemento de gran importancia para elevar el desempeño de estos profesionales. Resultados similares se encontraron en la bibliografía revisada. ${ }^{24,30}$

Tabla 9. Distribución de Directores de Áreas de Salud según horario de alimentación y sexo 2003

\begin{tabular}{|c|c|c|c|c|c|c|}
\hline \multirow{2}{*}{$\begin{array}{l}\text { Horario para alimentarse } \\
\text { en una semana laboral } \\
\text { tipo }\end{array}$} & \multicolumn{2}{|c|}{$\begin{array}{l}\text { Mujeres } \\
\mathrm{n}=124\end{array}$} & \multicolumn{2}{|c|}{$\begin{array}{c}\text { Hombres } \\
n=177\end{array}$} & \multicolumn{2}{|c|}{$\begin{array}{c}\text { Total } \\
\mathrm{n}=301\end{array}$} \\
\hline & No. & $\%$ & No. & $\%$ & No. & $\%$ \\
\hline Todos los días & 33 & 26,6 & 62 & 35,0 & 95 & 31,6 \\
\hline 3.a 4 días por semana & 64 & 51,6 & 78 & 44,1 & 142 & 47,2 \\
\hline 1.a 2 días a la semana & 24 & 19,4 & 34 & 19,2 & 58 & 19,3 \\
\hline Nunca & 3 & 2,4 & 3 & 1,7 & 6 & 1,9 \\
\hline
\end{tabular}

El 58,8\% de los directores refieren ser requeridos en horario nocturno por problemas de trabajo por lo menos una vez a la semana, con similar frecuencia para hombres $(57,6 \%)$ y mujeres $(60,5 \%)$ como se puede observar en la tabla 10 , lo que se comportó de forma homogénea por provincias. Esto está muy relacionado con todo lo analizado hasta el momento, lo que habla a favor de una mala organización y planificación del trabajo. En otras investigaciones ${ }^{28,30}$ se ha podido constatar resultados similares. 
Tabla 10. Distribución de Directores de Áreas de Salud según requerimientos en el domicilio y sexo. 2003

\begin{tabular}{|l|c|c|c|c|c|c|}
\hline \multirow{2}{*}{$\begin{array}{l}\text { Requerimientos en el domicilio por } \\
\text { problemas de trabajo en horario } \\
\text { nocturno }\end{array}$} & \multicolumn{2}{|c|}{$\begin{array}{l}\text { Mujeres } \\
n=124\end{array}$} & \multicolumn{2}{|c|}{$\begin{array}{c}\text { Hombres } \\
n=177\end{array}$} & \multicolumn{2}{c|}{$\begin{array}{c}\text { Total } \\
n=301\end{array}$} \\
\cline { 2 - 8 } & \multicolumn{2}{|c|}{} & \multicolumn{2}{|c|}{} \\
\cline { 2 - 8 } & No. & $\%$ & No. & $\%$ & No. & $\%$ \\
\hline Todas los días & 15 & 12,1 & 23 & 13,0 & 38 & 12,6 \\
\hline Todas las semanas & 60 & 48,4 & 79 & 44,6 & 139 & 46,2 \\
\hline $3-4$ veces al mes & 34 & 27,4 & 53 & 29,9 & 87 & 28,9 \\
\hline 1 vez al mes & 12 & 9,7 & 15 & 8,5 & 27 & 9,0 \\
\hline Nunca & 3 & 2,4 & 7 & 4,0 & 10 & 3,3 \\
\hline
\end{tabular}

En la distribución de las actividades planificadas para días no laborables en un mes tipo, se puso de manifiesto que los directores, tanto hombres como mujeres, planificaron trabajo en más del $80 \%$, como mínimo dos o tres veces al mes (tabla 11). Lo anterior se comportó de modo uniforme en las provincias.

Tabla 11. Distribución de Directores de Áreas de Salud según planificación del trabajo y sexo. 2003

\begin{tabular}{|c|c|c|c|c|c|c|}
\hline \multirow{2}{*}{$\begin{array}{l}\text { Planificación del trabajo para días no } \\
\text { laborales en un mes tipo }\end{array}$} & \multicolumn{2}{|c|}{$\begin{array}{l}\text { Mujeres } \\
\mathrm{n}=124\end{array}$} & \multicolumn{2}{|c|}{$\begin{array}{c}\text { Hombres } \\
\mathrm{n}=177\end{array}$} & \multicolumn{2}{|c|}{$\begin{array}{c}\text { Total } \\
\mathrm{n}=301\end{array}$} \\
\hline & No. & $\%$ & No. & $\%$ & No. & $\%$ \\
\hline Todas las semanas & 29 & 23,4 & 32 & 18,1 & 61 & 20,3 \\
\hline 2-3 veces al mes & 71 & 57,3 & 113 & 63,8 & 184 & 61,1 \\
\hline 1 vez al mes & 21 & 16,9 & 22 & 12,4 & 43 & 14,3 \\
\hline Nunca & 3 & 2,4 & 10 & 5,7 & 13 & 4,3 \\
\hline
\end{tabular}

Algunas respuestas que pudieran explicar este fenómeno serían las dificultades que tienen los directores de policlínicos para planificar correctamente su trabajo, lo que pudiera deberse a que este no tiene una buena organización posiblemente influenciada por el exceso de reuniones dentro y fuera del horario laboral, donde muchas no guardan relación con los objetivos de la institución y además, la falta de un equipo completo de dirección. Según el grupo de investigadores de la ENSAP los directores de policlínico perciben que en horario extralaboral sábados y domingos, dedican a la función administrativa más del $80 \%$ del tiempo. ${ }^{29}$

Sobre el tiempo dedicado al descanso y a la recreación. Entiéndase por descanso en este estudio, el tiempo dedicado a ver la TV, leer y compartir con la familia, y por recreación, el tiempo dedicado a ir a un cine, fiesta, teatro o practicar algún deporte tanto en días laborales como no laborales. En la tabla 12 se pone de manifiesto como de forma general los directores de áreas de salud el mayor tiempo que dedican al descanso es entre 2 y 3 h (62,3\%), sin embargo, como promedio en el país no dedican tiempo a la recreación el $74,1 \%$ y en las mujeres, más del 80 $\%$ no dedica tiempo a la recreación, esto último pudiera estar relacionado con la diferencia de roles donde la mujer dedica mayor cantidad de tiempo a labores del hogar. Esta situación tuvo un comportamiento semejante por provincias. 
Tabla 12. Distribución de Directores de Áreas de Salud según horario de descanso y recreación en días laborales y sexo. 2003

\begin{tabular}{|c|c|c|c|c|c|c|c|c|c|c|c|c|}
\hline \multirow{3}{*}{$\begin{array}{l}\text { Horario } \\
\text { de } \\
\text { descanso } \\
\text { y } \\
\text { recreación }\end{array}$} & \multicolumn{4}{|c|}{$\begin{array}{l}\text { Mujeres } \\
\mathrm{n}=124\end{array}$} & \multicolumn{4}{|c|}{$\begin{array}{c}\text { Hombres } \\
n=177\end{array}$} & \multicolumn{4}{|c|}{$\begin{array}{c}\text { Total } \\
\mathrm{n}=301\end{array}$} \\
\hline & \multicolumn{2}{|c|}{$\bar{D}$} & \multicolumn{2}{|c|}{$R$} & \multicolumn{2}{|c|}{$\bar{D}$} & \multicolumn{2}{|r|}{$R$} & \multicolumn{2}{|c|}{ D } & \multicolumn{2}{|c|}{$R$} \\
\hline & No. & $\%$ & No. & $\%$ & No. & $\%$ & No. & $\%$ & No. & 96 & No. & $\%$ \\
\hline $4-5 h$ & 12 & 9,7 & 6 & 4,8 & 25 & 14,1 & 10 & 5,6 & 37 & 12,3 & 16 & 5,3 \\
\hline $2-3 h$ & 77 & 62,1 & 16 & 12,9 & 112 & 63,3 & 46 & 26,0 & 189 & 62,8 & 62 & 20,6 \\
\hline $\begin{array}{l}\text { No dedica } \\
\text { tiempo }\end{array}$ & 35 & 28,2 & 102 & 82,3 & 40 & 22,6 & 121 & 68,4 & 75 & 24,9 & 223 & 74,1 \\
\hline
\end{tabular}

D: descanso, R: recreación.

En cuanto a las horas dedicadas al descanso y la recreación en días no laborables, se encontró que la mayoría, tanto hombres como mujeres dedicaron menos de $5 \mathrm{~h}$ al descanso $(42,2 \%)$ y que el $40,5 \%$ no dedicó tiempo a la recreación. Lo anterior tuvo mayor repercusión en las mujeres donde más del $45 \%$ no dedicó tiempo a la recreación los fines de semana (tabla 13). Es posible que las actividades de trabajo planificadas para los días no laborales, como se expresó anteriormente, y la diferencia de roles entre hombres y mujeres en el hogar y la comunidad pudieran influir en este comportamiento, lo que justificaría esta situación en las mujeres al tener el tiempo ocupado en otras tareas.

Tabla 13. Distribución de Directores de Áreas de Salud según horario de descanso y recreación en dias no laborales y sexo. 2003

\begin{tabular}{|c|c|c|c|c|c|c|c|c|c|c|c|c|}
\hline \multirow{3}{*}{$\begin{array}{l}\text { Horario } \\
\text { de } \\
\text { descanso } \\
\text { y } \\
\text { recreación }\end{array}$} & \multicolumn{4}{|c|}{$\begin{array}{l}\text { Mujeres } \\
n=124\end{array}$} & \multicolumn{4}{|c|}{$\begin{array}{l}\text { Hombres } \\
\mathrm{n}=177\end{array}$} & \multicolumn{4}{|c|}{$\begin{array}{l}\text { Total } \\
\mathrm{n}=301\end{array}$} \\
\hline & \multicolumn{2}{|c|}{ D } & \multicolumn{2}{|c|}{$R$} & \multicolumn{2}{|c|}{ D } & \multicolumn{2}{|c|}{$R$} & \multicolumn{2}{|c|}{$\mathrm{D}$} & \multicolumn{2}{|c|}{$R$} \\
\hline & No. & $\%$ & No. & $\%$ & No. & $\%$ & No. & $\%$ & No. & $\%$ & No. & $\%$ \\
\hline $15-19 \mathrm{~h}$ & 2 & 1,6 & 3 & 2,4 & 9 & 5,1 & 9 & 5,1 & 11 & 3,7 & 12 & 4,0 \\
\hline $10-15 \mathrm{~h}$ & 4 & 3,2 & 7 & 5,7 & 14 & 7,9 & 8 & 4,5 & 18 & 5,9 & 15 & 5,0 \\
\hline $5-9 h$ & 29 & 23,4 & 21 & 6,9 & 49 & 27,7 & 25 & 14,1 & 78 & 25,9 & 46 & 15,3 \\
\hline $\begin{array}{l}\text { Menos de } \\
5 \mathrm{~h}\end{array}$ & 55 & 44,4 & 37 & 29,8 & 72 & 40,7 & 69 & 39,0 & 127 & 42,2 & 106 & 35,2 \\
\hline $\begin{array}{l}\text { No dedica } \\
\text { tiempo }\end{array}$ & 34 & 27,4 & 56 & 45,2 & 33 & 18,6 & 66 & 3,3 & 67 & 22,3 & 122 & 40,5 \\
\hline
\end{tabular}

D: descanso, R: recreación.

Las actividades en el tiempo de descanso, tanto los días entre semana como los fines de semana, que los encuestados refirieron fueron: la mujer los empleó principalmente en compartir con la familia, escuchar radio y ver TV, y este último 
constituyó para ellas la principal vía de información, sin embargo, en el caso de los hombres este tiempo se dedicó fundamentalmente a leer. En las actividades de recreación, coincidió en ambos sexos, que el tiempo que lograron dedicarle, lo emplearon en compartir con amigos.

Referente a las actividades de superación, donde se incluyó el autoestudio, se comprobó, como se aprecia en la tabla 14, que el 40,5\% de los directores refirieron dedicar a esta actividad una frecuencia de una vez por semana, en mayor cuantía en las mujeres $(47,6 \%)$, que en los hombres $(35,6 \%)$.

Tabla 14. Distribución de Directores de Áreas de Salud según tiempo dedicado a su superación en un mes tipo por sexo. 2003

\begin{tabular}{|l|c|c|c|c|c|c|}
\hline \multirow{2}{*}{ Horario } & \multicolumn{2}{|c|}{$\begin{array}{c}\text { Mujeres } \\
n=124\end{array}$} & \multicolumn{2}{c|}{$\begin{array}{c}\text { Hombres } \\
n=177\end{array}$} & \multicolumn{2}{c|}{$\begin{array}{c}\text { Total } \\
n=301\end{array}$} \\
\cline { 2 - 7 } & No. & $\%$ & No. & $\%$ & No. & $\%$ \\
\hline Más de 1 vez por semana & 26 & 21,0 & 62 & 35,0 & 88 & 29,2 \\
\hline 1 vez por semana & 59 & 47,6 & 63 & 35,6 & 122 & 40,5 \\
\hline 1 vez cada 15 días & 15 & 12,1 & 32 & 18,1 & 47 & 15,6 \\
\hline 1 vez al mes & 21 & 16,9 & 15 & 8,5 & 36 & 12,0 \\
\hline No dedica tiempo & 3 & 2,4 & 5 & 2,8 & 8 & 2,7 \\
\hline
\end{tabular}

Las actividades de superación que realizaron estaban en correspondencia con aspectos de la profesión en más del 70 \%. Esta realidad merece una reflexión, ya que para la situación actual en la Salud Pública, es necesario por la importancia que reviste, dedicar más tiempo a la capacitación y preparación de los cuadros directivos con elementos de dirección en salud que le permita una buena planificación y organización del trabajo si se aspira a que los dirigentes sean altamente competentes (tabla 14).

Los cuadros en Cuba, según la política de cuadro en el país, deben someterse periódicamente a un examen médico de control de salud. En tabla 15 se puede apreciar que el $14,6 \%$ de los directores en ambos sexos, nunca se ha realizado este examen médico.

Tabla 15. Distribución de Directores de Áreas de Salud según el momento en que se realizó el chequeo médico por sexo. 2003

\begin{tabular}{|c|c|c|c|c|c|c|}
\hline \multirow[t]{2}{*}{$\begin{array}{l}\text { Momento del examen médico de control } \\
\text { de salud }\end{array}$} & \multicolumn{2}{|c|}{$\begin{array}{l}\text { Mujeres } \\
n=124\end{array}$} & \multicolumn{2}{|c|}{$\begin{array}{l}\text { Hombres } \\
\mathrm{n}=177\end{array}$} & \multicolumn{2}{|c|}{$\begin{array}{l}\text { Total } \\
\mathrm{n}=301\end{array}$} \\
\hline & No. & $\%$ & No. & $\%$ & No. & $\%$ \\
\hline Primer trimestre 2003 & 29 & 23,4 & 42 & 23,7 & 71 & 23,6 \\
\hline En el 2002 & 27 & 21,8 & 35 & 19,8 & 62 & 20,6 \\
\hline $\begin{array}{l}\text { Hace más de un año que no se realiza } \\
\text { el examen médico }\end{array}$ & 54 & 43,5 & 70 & 39,5 & 124 & 41,2 \\
\hline $\begin{array}{l}\text { Nunca se ha realizado } \\
\text { el examen médico }\end{array}$ & 14 & 11,3 & 30 & 17,0 & 44 & 14,6 \\
\hline
\end{tabular}


Las percepciones y respuestas que abarcan el Clima Organizacional se originan en una gran variedad de factores. ${ }^{21}$ Para el cumplimiento del objetivo 2 se aplicó un inventario de clima organizacional diseñado por el programa sub-regional para el desarrollo de la capacidad gerencial en los servicios de salud de Centroamérica. Este instrumento se aplicó en estudios anteriores con directores de policlínico y municipales en Ciudad de la Habana con buenos resultados, ${ }^{24,30}$ lo que decidió su aplicación en este estudio. Lo anterior posibilitaría la compararación de los datos alcanzados en Ciudad de la Habana con los encontrados en el resto del país.

La herramienta evaluativa consta de cuatro dimensiones básicas: motivación, liderazgo, reciprocidad y participación. A su vez estas dimensiones se subdividen en cuatro categorías cada una, que son abordados a través de cinco incisos que conllevan a una puntuación que oscila entre 0 y 5 puntos. Se toma como valor mínimo aceptable la puntuación de 3.

La primera dimensión estudiada fue el liderazgo, en ella se valoraron las siguientes categorías: dirección, estímulo a la excelencia, estímulo al trabajo en equipo y solución de conflictos. Los valores medios de cada una de estas categorías permitieron identificar la percepción sobre el liderazgo en los directores de policlínico. Esta dimensión arrojó valores cercanos a la cifra mínima aceptable, entre 3,2 y 3,9 (figura 1). Según los resultados de la dimensión explorada, se puede decir que los directores de áreas de salud percibieron tener la capacidad de asumir la responsabilidad para conducir a otros al logro de los fines de la institución, sobre todo, estimulando el trabajo en equipo que como se puede observar fue la categoría de mejor resultado.

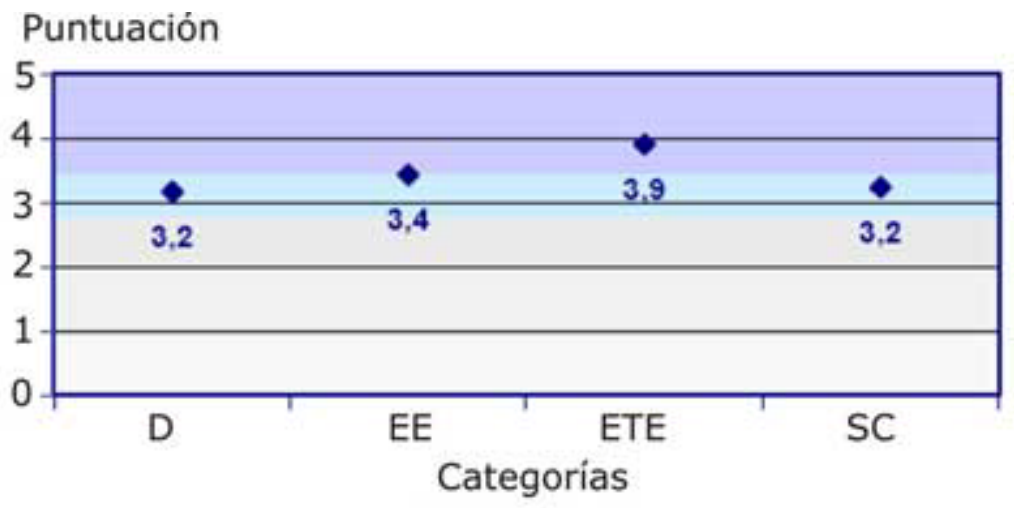

D: dirección. EE: estímulo a la excelencia. ETE: estímulo al trabajo en equipo.SC: solución de conflictos.

Fig. 1. Comportamiento de la dimensión Liderazgo.

Las categorías de menor puntuación dentro la dimensión liderazgo, fueron: dirección y la solución de conflictos, ambas con 3,2 puntos como promedio. Dentro el elemento dirección, el inciso que más baja puntuación acumuló estuvo relacionado con el planteamiento de los directores de "que por lo general, tienen muchas cosas que hacer y no saben por cuál empezar." Mientras que en la solución de conflictos, el inciso que influyó en la baja puntuación fue la opinión de que "cuando se analiza un problema, las posiciones que adoptan los compañeros no siempre son sinceras". Esto coincidió con el estudio que realizó Presno en Ciudad de la Habana. 24 
La segunda dimensión estudiada fue la motivación, dentro de esta se valoraron las categorías: realización personal, reconocimiento de la aportación, responsabilidad y adecuación de las condiciones de trabajo. Los resultados colocaron a esta dimensión en valores inaceptables con cifras entre 2,9 y 1,3, por debajo del límite inferior medio aceptado, como se puede verse en la figura 2.

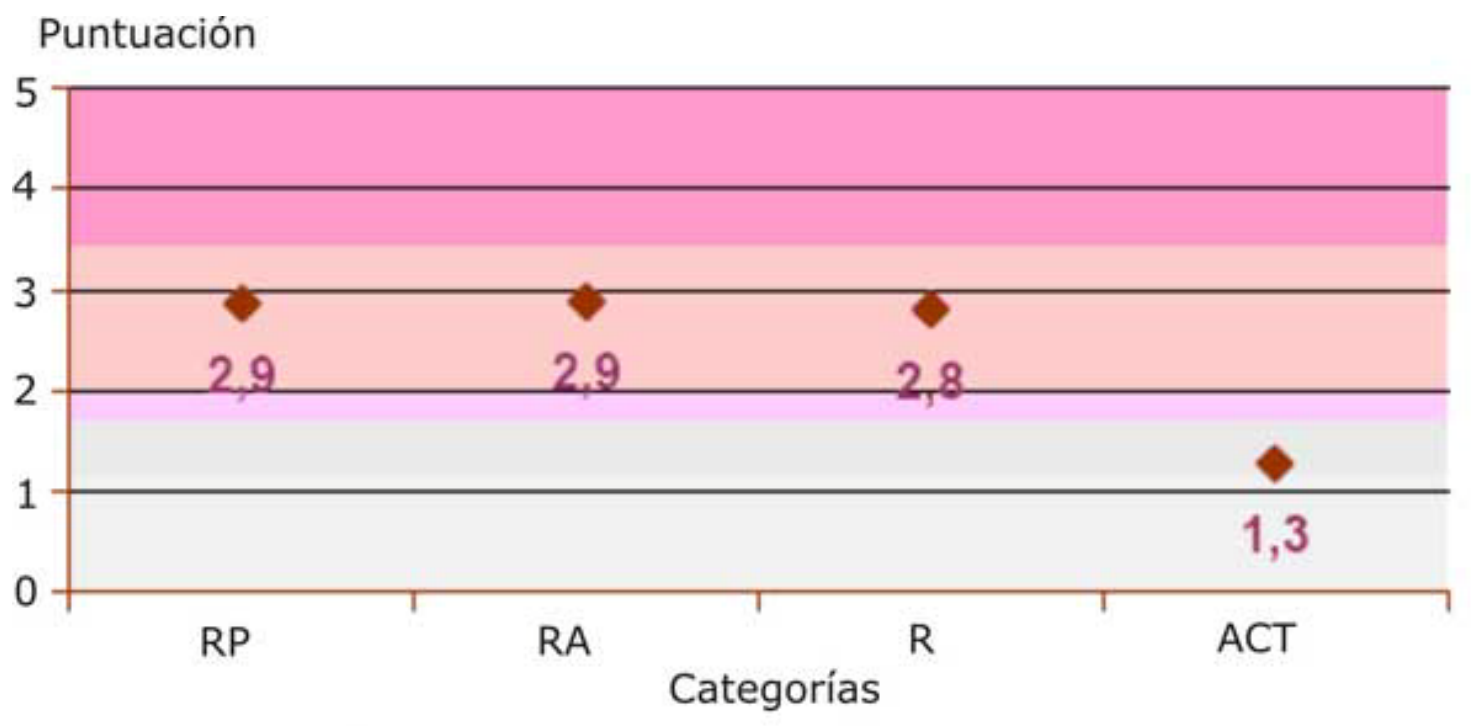

\section{RP: realización personal.RA: reconocimiento de la aportación.R: responsabilidad.ACT: adecuación de las condiciones de trabajo.}

\section{Fig. 2. Comportamiento de la dimensión Motivación.}

La categoría de menor valor en esta dimensión fue la adecuación de la condiciones de trabajo, donde se recogieron las siguientes opiniones: "las condiciones de trabajo no son buenas, no se cuenta con los elementos de trabajo necesarios, el ambiente que se respira en el trabajo es tenso, no se sienten satisfechos con el ambiente físico en que se trabaja y se dedica poco tiempo para revisar con los directores que se requiere para mejorar su desempeño". Pudiera pensarse que estas opiniones están fundamentadas con lo expuesto anteriormente en relación con la disponibilidad de recursos para el cumplimiento de sus funciones (tabla 6).

La segunda categoría de menor puntación fue la responsabilidad, con un valor de 2,8 , por debajo de límites normales (figura 2). Se destacó de forma negativa el que los directores expresaran que "casi la gran mayoría de ellos hace el trabajo como mejor les parece", lo que habla a favor de que no poseen el conocimiento necesario para planificar y organizar sus actividades. Lo anterior pudiera guardar relación con el proceso superación de los cuadros o estar vinculado con la percepción que tienen del poco reconocimiento por la labor desempeñada. Esto último también se manifestó en las categorías reconocimiento a la aportación y realización personal puesto que perciben "que no pueden desarrollar su ingenio y creatividad". Estos resultados coincidieron con los de Presno en el año $1997 .{ }^{24}$

La relación de dar y recibir mutuamente entre el individuo y la organización es lo que se explora en la dimensión reciprocidad. Aquí se estudian las categorías: aplicación al trabajo, cuidado del patrimonio institucional, retribución y equidad. La categoría que obtuvo la mejor puntuación fue el cuidado al patrimonio institucional que habla a favor del compromiso que manifestaron los directores en el cuidado de la propiedad social. Las categorías de menor valor fueron la aplicación al trabajo 
con 2,4 y retribución con 2,8; ambos por debajo del límite inferior aceptado ( $3)$.

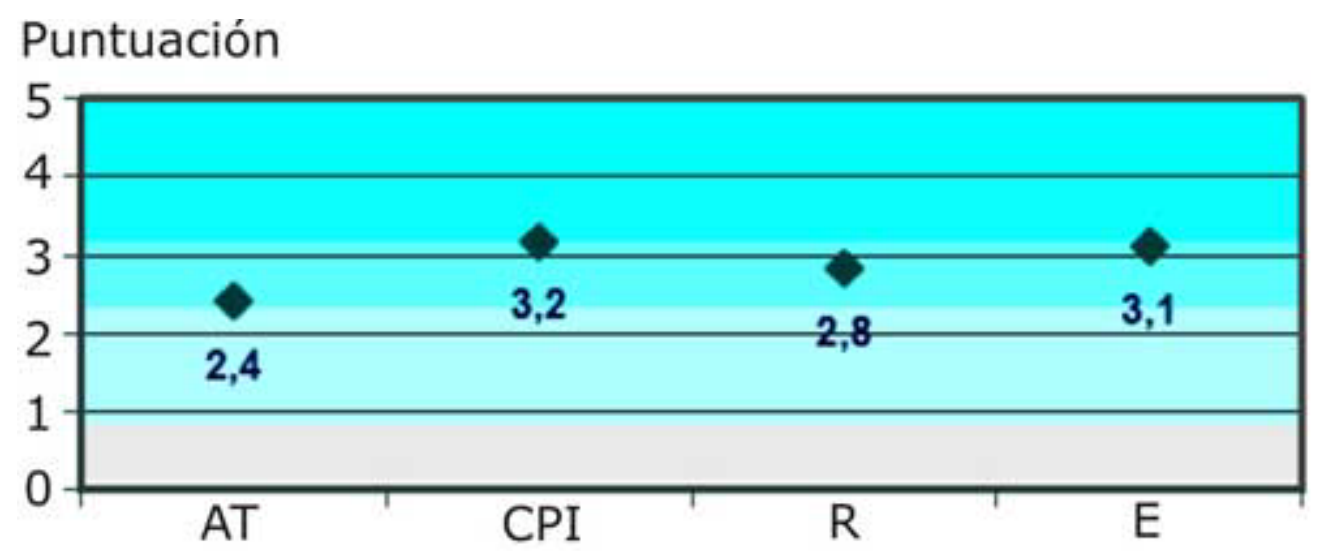

\section{Categorías}

\section{AT: aplicación al trabajo. CPI: cuidado del patrimonio institucional. R: retribución. E: equidad}

\section{Fig. 3. Comportamiento de la dimensión Reciprocidad.}

En la aplicación al trabajo se señalaron aspectos tales como: "no se esfuerzan para cumplir a cabalidad con sus obligaciones, no se sienten auto motivados en el trabajo y no les interesa hacerse cargo de los trabajos importantes."

En el componente retribución se recogieron las siguientes respuestas: "por lo general, las personas que trabajan bien no son premiadas o reconocidas por la organización, y plantearon además, que no siempre se ofrecen buenas oportunidades de capacitación para el personal que dirige en el nivel primario de salud. "

Finalmente se investigó la participación que conforma la 4ta. dimensión del instrumento que se utilizó, dentro de esta dimensión se midieron los siguientes elementos: compromiso con la productividad, compatibilidad de intereses, intercambio de información e involucrarse en el cambio.

El componente con puntuación por debajo de lo establecido como normal es el que investigó los aspectos relacionados con el compromiso de la productividad con 2,8 como se observa en la figura 4. 


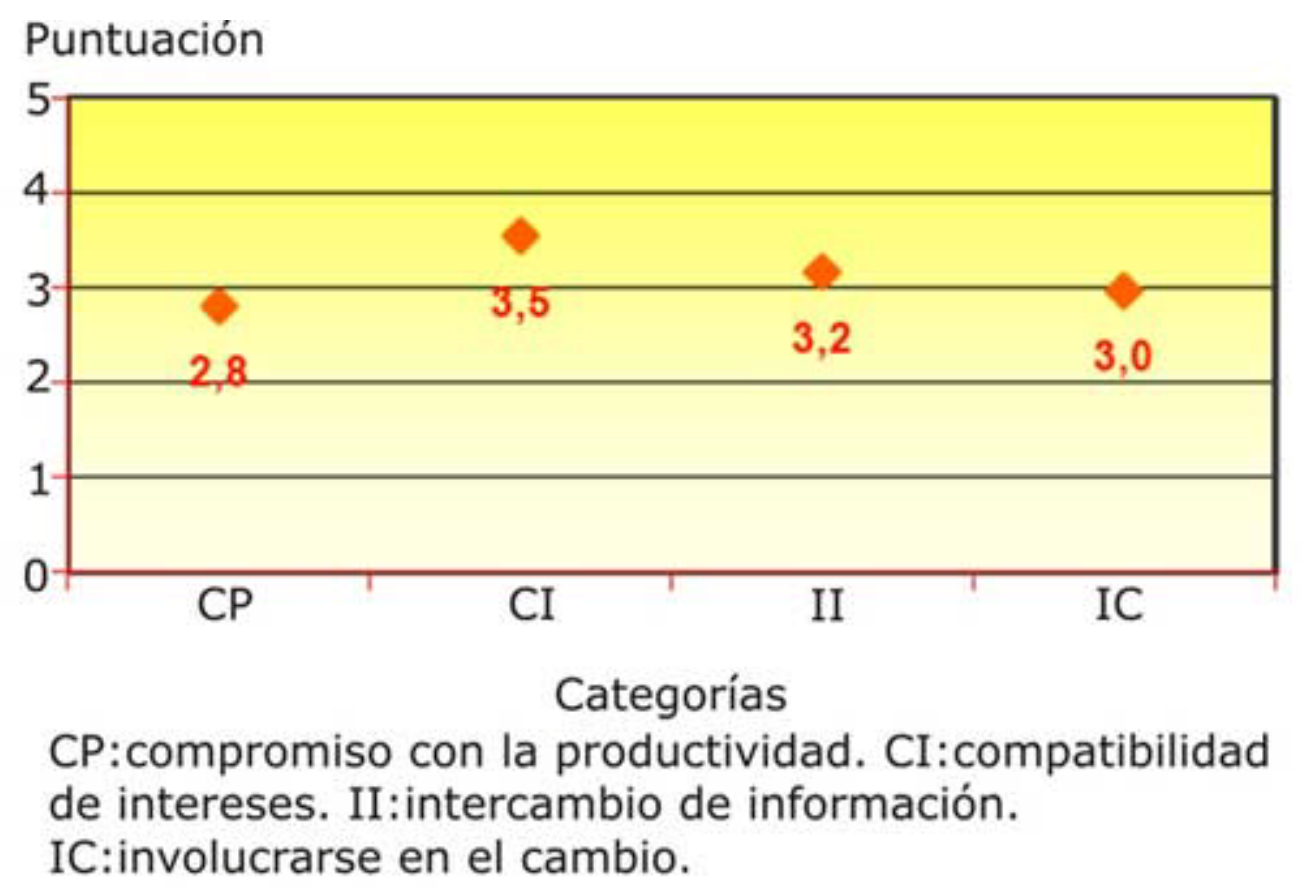

Fig. 4. Comportamiento de la dimensión Participación.

Dentro los aspectos que influyeron en esta puntuación de la categoría compromiso con la productividad, hay que señalar, que los directores de áreas de salud manifestaron que "los diferentes niveles jerárquicos de la organización no colaboran con ellos y que no existe espíritu de trabajo en equipo, por lo que los problemas que surgen entre los grupos de trabajo no siempre se pueden resolver de manera optima". Los restantes componentes dentro de la dimensión obtuvieron valores entre 3 y 3,5 .

Hay que destacar de forma positiva lo que se expresó en el componente compatibilización de intereses $(3,5)$ en relación con "los objetivos de los policlínicos eran congruentes con los objetivos del municipio en materia de salud", este fue el inciso de mayor puntuación dentro la categoría.

En resumen, puede plantearse que:

- Las direcciones de áreas de salud en el país están cubiertas por personal joven a predominio masculino y con menos de 3 años en el cargo. Estos provienen promovidos de otro cargo o de la atención directa a la población al estar incluido en la reserva de cuadro; y manifiestan no sentirse totalmente preparados para asumir la responsabilidad.

- No cuentan con los equipos de dirección completos lo que dificulta el desempeño adecuado de sus funciones.

- Dedican más de la mitad del tiempo a reunirse fuera y dentro del horario laboral y no siempre, estas reuniones, responden directamente con los objetivos de la institución.

- La organización del trabajo en las áreas de salud limita el tiempo que se dedica para alimentación, descanso, recreación y superación de los directores, lo que demuestra falta de preparación en técnicas de dirección.

- En las dimensiones del clima organizacional que se estudiaron en los directores de áreas de salud, el mejor comportamiento lo manifiesta la dimensión liderazgo con todas sus categorías por encima del valor límite establecido y el peor resultado lo aporta la dimensión motivación con todas 
sus categorías por debajo del punto mínimo aceptable establecido, lo que pone de manifiesto que existe un debilitamiento en la voluntad y capacidad de este personal para realizar altos esfuerzos encaminados a alcanzar los objetivos de la institución, a pesar de que reconocen tener la capacidad necesaria para asumir tal responsabilidad. Está percepción se corresponde con los problemas estructurales y organizacionales identificados en este trabajo.

- Es recomendable diseñar, previa coordinación con la Dirección Nacional de Cuadros y Atención Primaria de Salud, un sistema de preparación en dirección que responda a las necesidades de cada puesto de dirección en este nivel de atención y donde se involucren los cuadros y sus reservas, y además, diseñar una estrategia de cambio organizacional donde se proponga un remodelación de la organización del trabajo para las direcciones de áreas de salud.

\section{Anexo 1}

Ministerio de Salud Pública

Escuela Nacional de Salud Pública

Compañero (a):

La Escuela Nacional de Salud Pública está realizando una investigación sobre los aspectos organizativos del Sistema Gerencial de la Atención Primaria de salud en el país, para lo cual necesitamos la cooperación para responder el siguiente cuestionario que le presentamos.

Muchas Gracias.

Datos generales

Municipio:

1. Sexo 2. Edad

3. Tiempo en el cargo

4. Estado civil

$\mathrm{F}_{----}<30$ años $<$ de 1 año Casado

M_--- 30-35 años 1 - 3 años Soltero

36-40 años 4 - 5 años Divorciado

41-59 años $>5$ años Unión Consensual

60 y más Viudo

5. Número de Hijos: 1 2 3 ó más No tiene Hijos:

Área Organización del Trabajo 
Marque con una $X$ la respuesta que corresponda. Seleccione una sola opción de las que se presentan, excepto en los casos en que se especifique:

1. Usted accedió al cargo que ocupa en la actualidad procedente de:

a) ___ La atención directa a la población, por estar incluido en la reserva de cuadros.

b) ___ La atención directa a la población sin estar incluido en la reserva de cuadros.

c) __-_ Promovido de otro cargo.

d) _--- Otras. Especifique:

- Si las respuestas son a ó c, diga si se ha sentido preparado para asumir el cargo. Fundamente.

2. Para desempeñar su trabajo usted dispone de: (puede marcar más de una opción)
a) __-_ Local adecuado.
c) __-_ Equipo de dirección completo.
d) __-_ Asesores.
e) _-_ Otras facilidades: especifique:

3. Las reuniones a las que asiste, generalmente se realizan:
a) _--_ Dentro del horario laboral.
b) __-_ Fuera del horario laboral.
c) __- Dentro y fuera del horario laboral.

o Si su respuesta es el inciso c) diga que tiempo fuera del horario laboral se extienden estas reuniones, como promedio:

4. De las reuniones que asiste, considera se relacionan directamente con los objetivos de su institución.
a) _--- Todas.
b) __-_ La mayoría.
c) _--- Algunas.
d) _-_ Ninguna. 
5. En una semana laboral tipo, tiene posibilidades de disponer de horario para alimentarse:
a) __-_ Todos los días.
b) __- 3 - 4 veces / semana.
c) __- 1 - 2 veces / semana.
d) __-_ Ningún día de la semana.

6. En una semana tipo, lo llaman o lo buscan en su domicilio en horario nocturno por problemas de trabajo:
a) _-_ Todos los días.
b) __-_ Todas las semanas.
c) _-_- 3 - 4 veces / mes.
d) _-_- 1 vez al mes.
e) ___ Nunca.

7. En un mes de trabajo tipo, tiene planificado trabajo para todos los días no laborables:
a) _-_ Todas las semanas.
b) _-- 2 - 3 veces / mes.
c) ___ 1 vez al mes.
d) _-_ Nunca.

8. Los días laborables dedica al descanso y a la recreación regularmente (no se considera el sueño nocturno)

\section{Descanso Recreación}

a) 4 - 5 horas

b) 2 - 3 horas

c) no dedica tiempo

Descanso: ver TV, leer, compartir con la familia, escuchar radio.

Recreación: ir al cine, una fiesta, teatro, a un restaurante, compartir con amigos, realizar deporte.

Exponga que actividades fundamentalmente realiza. 
9. Los días no laborables dedica al descanso y a la recreación regularmente (no se considera el sueño nocturno):

$$
\text { Descanso Recreación }
$$

a) más de 20 horas

b) $15-19$ horas

c) $10-15$ horas

d) 5 - 9 horas

e) menos de 5 horas

10. De un mes laboral tipo, dedica a actividades de superación (incluyendo autoestudio) como promedio:

a) __-_ Más de una vez / semana.

b) __-_ 1 vez / semana.

c) ____ 1vez cada 15 días.

d) _-_- 1 vez / mes.

e) ___- No dedica tiempo a la superación.

Las actividades de superación que realiza guardan relación:

_-_ con su profesión

_-_ con el puesto de dirección que desempeña actualmente

--- otras

(Marque con una $\mathrm{X}$ las repuestas correctas, puede marcar más de una opción.)

11. El último examen médico de control de salud para evaluar su estado de salud lo realizó:

a) ___ Primer trimestre del 2003.

b) __-_ En 2002 .

c) ___. Hace más de un año que no me realizó el examen médico de control de salud.

d) __-_ Nunca me he realizado el examen médico de control de salud. 


\section{Anexo 2}

\section{Clima Organizacional}

Este cuestionario forma parte de una investigación sobre el clima organizacional. Contiene una serie de reflexiones o afirmaciones, que son comunes dentro de la organización. Su colaboración consiste en relacionar cada una de estas afirmaciones con la realidad de su grupo de trabajo. Sus respuestas son estrictamente confidenciales; usted no tendrá que compartir nominalmente sus respuestas.

Lea cuidadosamente cada una de estas afirmaciones y establezca si se aplican o no a su unidad de trabajo en la organización. Si la reflexión se aplica, marque la $\mathrm{V}$ (verdadero) . o en caso contrario marque la $\mathrm{F}$ (falso). Trabaje cuidadosamente pues ello dependerá el éxito de este ejercicio. Cuando tenga una duda sobre la respuesta, haga una marca provisional y regrese posteriormente a esta afirma ción. Marque una sola respuesta sea lo más honestos y objetivos.

Les agradecemos de antemano la ayuda y colaboración que presta al realizar el presente ejercicio, con el cual se espera contribuir al mejoramiento de su organización.

\begin{tabular}{|c|c|c|c|}
\hline 1 & $V_{-}$ & $F_{--}$ & Mi superior se preocupa porque entendamos bien el trabajo. \\
\hline 2 & $\mathrm{~V}$ & $\mathrm{~F}_{--}$ & Generalmente, se aceptan las ideas para mejorar el trabajo. \\
\hline 3 & $V_{-}$ & $\mathrm{F}_{--}$ & La mayoría de los trabajos que realizamos exigen raciocinio. \\
\hline 4 & $\mathrm{~V}_{-}$ & $F_{--}$ & $\begin{array}{l}\text { En esta organización se busca que cada cual tome decisiones } \\
\text { de cómo realizar mejor su trabajo }\end{array}$ \\
\hline 5 & $V_{-}$ & $F_{--}$ & El ambiente que se respira en este trabajo es tenso. \\
\hline 6 & $V_{-}$ & $F_{--}$ & $\begin{array}{l}\text { Todos en este territorio se esfuerzan por cumplir a cabalidad } \\
\text { con sus obligaciones. }\end{array}$ \\
\hline 7 & $V_{-}$ & $F_{--}$ & $\begin{array}{l}\text { Con frecuencia mis compañeros hablan mal del trabajo que } \\
\text { realizan. }\end{array}$ \\
\hline 8 & $V_{-}$ & $\mathrm{F}_{--}$ & $\begin{array}{l}\text { En este municipio se ofrecen buenas oportunidades de } \\
\text { capacitación. }\end{array}$ \\
\hline 9 & $V_{--}$ & $F_{--}$ & Aquí las promociones carecen de objetividad. \\
\hline 10 & $V_{-}$ & $F_{-1}$ & $\begin{array}{l}\text { Los problemas que surgen entre los grupos de trabajos se } \\
\text { resuelven de manera óptima para la organización. }\end{array}$ \\
\hline 11 & $V_{--}$ & $F_{--}$ & $\begin{array}{l}\text { Los objetivos de la institución son congruentes con los } \\
\text { objetivos del municipio en materia de salud. }\end{array}$ \\
\hline 12 & $V_{--}$ & $F_{--}$ & $\begin{array}{l}\text { La información requerida para cumplir con nuestra función } \\
\text { fluye lentamente. }\end{array}$ \\
\hline 13 & $V_{--}$ & $F_{--}$ & La adopción de nuevas iniciativas se mira con recelo. \\
\hline 14 & $V_{-}$ & $F_{--}$ & $\begin{array}{l}\text { Ocurre con frecuencia que cuando se presenta un problema } \\
\text { determinado no se sabe quién debe resolverlo. }\end{array}$ \\
\hline 15 & $V_{-1}$ & $\mathrm{~F}_{--}$ & $\begin{array}{l}\text { Aquí se preocupan por mantener informado al personal } \\
\text { dirigente de los métodos y las tecnologías de dirección, con el }\end{array}$ \\
\hline
\end{tabular}




\begin{tabular}{|c|c|c|c|}
\hline & & & fin de mejorar la calidad y gestión. \\
\hline 16 & $V_{--}$ & $\mathrm{F}_{-}$ & $\begin{array}{l}\text { Aquí todos los problemas se discuten de una manera } \\
\text { constructiva. }\end{array}$ \\
\hline 17 & $V_{--}$ & $\mathrm{F}_{-}$ & $\begin{array}{l}\text { Para cumplir con las metas de trabajo tenemos que recurrir a } \\
\text { todas nuestras capacidades. }\end{array}$ \\
\hline 18 & $V_{-}$ & $\mathrm{F}_{--}$ & Con este trabajo me siento realizado profesionalmente. \\
\hline 19 & $V_{-}$ & $\mathrm{F}_{--}$ & En este municipio se premia a las personas que trabajan bien. \\
\hline 20 & $V_{--}$ & $F_{--}$ & $\begin{array}{l}\text { En general, nunca se ejcutan las ideas que damos sobre el } \\
\text { mejoramiento del trabajo. }\end{array}$ \\
\hline 21 & $V_{-}$ & $\mathrm{F}_{--}$ & Las condiciones de trabajo son buenas. \\
\hline 22 & $V_{--}$ & $\mathrm{F}_{--}$ & Aquí uno se siente automotivado en el trabajo. \\
\hline 23 & $V_{--}$ & $F_{--}$ & En nuestra organización se trabaja con orden. \\
\hline 24 & $V_{--}$ & $F_{--}$ & Yo me siento muy motivado para dirigir este territorio. \\
\hline 25 & $V_{--}$ & $\mathrm{F}_{--}$ & Las normas disciplinarias se aplican con subjetividad. \\
\hline 26 & $V_{-1}$ & $\mathrm{~F}_{-}$ & $\begin{array}{l}\text { Cuando hay un reto para la organización todas las áreas } \\
\text { participan activamente en la solución. }\end{array}$ \\
\hline 27 & $V_{-}$ & $\mathrm{F}_{-}$ & $\begin{array}{l}\text { Lo importante es cumplir los objetivos de la organización, lo } \\
\text { demás no interesa. }\end{array}$ \\
\hline 28 & $V_{--}$ & $\mathrm{F}_{-1}$ & $\begin{array}{l}\text { Generalmente, cuando se va hacer algo, los directores somos } \\
\text { los últimos en enterarnos. }\end{array}$ \\
\hline 29 & $V_{--}$ & $F_{--}$ & $\begin{array}{l}\text { Las iniciativas de las áreas no reciben respaldo de los nieveles } \\
\text { superiores. }\end{array}$ \\
\hline 30 & $V_{--}$ & $F_{--}$ & $\begin{array}{l}\text { Si un trabajo orientado parece difícil, se retarda hasta donde } \\
\text { se pueda. }\end{array}$ \\
\hline 31 & $V_{--}$ & $F_{--}$ & $\begin{array}{l}\text { A nuestro superior únicamente le podemos decir lo que quiere } \\
\text { oír. }\end{array}$ \\
\hline 32 & $V_{--}$ & $F_{--}$ & En esta organización el valor de los funcionarios es reconocido. \\
\hline 33 & $V_{--}$ & $\mathrm{F}_{-1}$ & $\begin{array}{l}\text { No existe una determinación clara de las funciones que cada } \\
\text { uno debe desempeñar. }\end{array}$ \\
\hline 34 & $V_{--}$ & $F_{-1}$ & $\begin{array}{l}\text { Casi nadie ahorra esfuerzo en el cumplimiento de sus } \\
\text { obligaciones. }\end{array}$ \\
\hline 35 & $V_{--}$ & $\mid F_{--}$ & Cuando uno no sabe como hacer algo, nadie lo ayuda. \\
\hline 36 & $V_{--}$ & $\mid F_{--}$ & Cuando tenemos un problema nadie se interesa por resolverlo. \\
\hline 37 & $V_{--}$ & $F_{--}$ & Existe poca libertad de acción para la realización del trabajo. \\
\hline 38 & $V_{--}$ & $F_{--}$ & $\begin{array}{l}\text { Existen grupos cuyas normas y valores no favorecen el trabajo } \\
\text { de la organización. }\end{array}$ \\
\hline 39 & $V_{--}$ & $F_{-1}$ & $\begin{array}{l}\text { Los programas de desarrollo de los dirigentes de esta } \\
\text { organización están trazados y preparan a los funcionarios para } \\
\text { avanzar dentro de su trabajo. }\end{array}$ \\
\hline 40 & $V_{--}$ & $F_{--}$ & Aquí únicamente están pendiente de los errores. \\
\hline 41 & $V_{--}$ & $\mathrm{F}_{-}$ & $\begin{array}{l}\text { Poco tiempo es dedicado a revisar con los dirigentes que se } \\
\text { requiere paa mejorar su desempeño. }\end{array}$ \\
\hline 42 & $V_{-}$ & $F_{--}$ & En general, el trabajo se hace superficial y mediocre. \\
\hline 43 & $V_{-}$ & $F_{--}$ & Casi todos hacen un trabajo como mejor les parece. \\
\hline 44 & $V_{--}$ & $F_{--}$ & Se trata con respeto y diligencia a los usuarios de nuestros \\
\hline
\end{tabular}




\begin{tabular}{|c|c|c|c|}
\hline & & & servicios. \\
\hline 45 & $V_{--}$ & $\mathrm{F}_{-}$ & $\begin{array}{l}\text { La eficiencia en el trabajo no implica reconocimiento de } \\
\text { ninguna clase. }\end{array}$ \\
\hline 46 & $V_{--}$ & $\mathrm{F}_{--}$ & Aquí cada esfera trabaja por su lado. \\
\hline 47 & $V_{-}$ & $\mathrm{F}_{--}$ & Aquí el poder está concentrado en unas pocoas personas. \\
\hline 48 & $V_{-}$ & $\mathrm{F}_{-1}$ & $\begin{array}{l}\text { Periódicamente tenemos problemas debido a la circulación de } \\
\text { información inexacta (chismes, rumores). }\end{array}$ \\
\hline 49 & $V_{-}$ & $\mathrm{F}_{--}$ & Aquí uno no puede desarrollar su ingenio y creatividad. \\
\hline 50 & $V_{-}$ & $F_{--}$ & Nuestro jefe es comprensivo, pero exige muy poco. \\
\hline 51 & $V_{--}$ & $\mathrm{F}_{-}$ & $\begin{array}{l}\text { A menudo se inician trabajos que no se saben por qué se } \\
\text { hacen. }\end{array}$ \\
\hline 52 & $V_{-}$ & $F_{--}$ & $\begin{array}{l}\text { Mi superior no se preocupa por que se aporten ideas que } \\
\text { mejoran la calidad del trabajo. }\end{array}$ \\
\hline 53 & $V_{-}$ & $F_{--}$ & Los programas de capacitación son patrimonio de unos pocos. \\
\hline 54 & $V_{-1}$ & $\mathrm{~F}_{-}$ & $\begin{array}{l}\text { En esta organización, ser promovido significa poder enfrentar } \\
\text { desafíos mayores. }\end{array}$ \\
\hline 55 & $V_{-}$ & $\mathrm{F}_{-}$ & $\begin{array}{l}\text { Los problemas se analizan siguiendo métodos sistemáticos } \\
\text { para encontrar soluciones creativas. }\end{array}$ \\
\hline 56 & $V_{--}$ & $\mathrm{F}_{-1}$ & $\begin{array}{l}\text { La dedicación del colectivo de dirección de este territorio } \\
\text { merece reconocimiento. }\end{array}$ \\
\hline 57 & $V_{--}$ & $F_{--}$ & $\begin{array}{l}\text { Toda la decisión que se toma es necesario consultarla con los } \\
\text { superiores antes de ponerla en práctica. }\end{array}$ \\
\hline 58 & $V_{--}$ & $F_{--}$ & $\begin{array}{l}\text { Normalmente las personas se responsabilizan de controlar su } \\
\text { propio trabajo. }\end{array}$ \\
\hline 59 & $V_{--}$ & $F_{--}$ & $\begin{array}{l}\text { La mayoría significativa de los funcionarios de esta } \\
\text { organización nos sentimos satisfechos con el ambiente físico } \\
\text { en el que se trabaja. }\end{array}$ \\
\hline 60 & $V_{--}$ & $F_{-1}$ & $\begin{array}{l}\text { Defendemos con vehemencia el trabajo y la imagen de nuestra } \\
\text { organización. }\end{array}$ \\
\hline 61 & $V_{--}$ & $\mathrm{F}_{--}$ & El espíritu de equipo en esta organización es excelente. \\
\hline 62 & $V_{--}$ & $F_{-1}$ & $\begin{array}{l}\text { Los recursos limitados de nuestras áreas, los compartimos } \\
\text { fácilmente con otras instituciones del territorio. }\end{array}$ \\
\hline 63 & $V_{--}$ & $F_{--}$ & Los que poseen la información no la dan a conocer fácilmente. \\
\hline 64 & $V_{--}$ & $F_{--}$ & $\begin{array}{l}\text { En esta organización existen grupos que se oponen a todos los } \\
\text { cambios. }\end{array}$ \\
\hline 65 & $V_{--}$ & $F_{--}$ & Cada uno cuenta con los elementos de trabajos necesarios. \\
\hline 66 & $V_{-}$ & $\mathrm{F}_{-}$ & $\begin{array}{l}\text { Por lo general, las personas que trabajan bien son reconocidas } \\
\text { con una mejor posición en la organización. }\end{array}$ \\
\hline 67 & $V_{-1}$ & $\mathrm{~F}_{-}$ & $\begin{array}{l}\text { Por lo general, tenemos muchas cosas que hacer y no } \\
\text { sabemos por cuál empezar. }\end{array}$ \\
\hline 68 & $V_{--}$ & $\mathrm{F}_{--}$ & $\begin{array}{l}\text { Cuando analizamos un problema las posiciones que adoptan } \\
\text { mis compañeros no siempre son sinceras. }\end{array}$ \\
\hline 69 & $V_{--}$ & & $\begin{array}{l}\text { Normalmente se da un reconocimiento especial por el buen } \\
\text { desempeño del trabajo. }\end{array}$ \\
\hline 70 & $V_{--}$ & $F_{--}$ & A mi jefe no le preocupa la calidad del trabajo. \\
\hline 71 & $V_{--}$ & $F_{--}$ & A la gente le gusta hacerse cargo de los trabajos importantes. \\
\hline
\end{tabular}




\begin{tabular}{|c|c|c|l|l|}
\hline 72 & $V_{--}$ & $F_{--}$ & $\begin{array}{l}\text { En general, todos tratan con cuidado los bienes de la } \\
\text { organización }\end{array}$ \\
\hline 73 & $V_{--}$ & $F_{--}$ & Aquí los resultados son frutos del trabajo de unos pocos. \\
\hline 74 & $V_{--}$ & $F_{--}$ & $\begin{array}{l}\text { Los trabajadores se sienten orgullosos de pertenecer a esta } \\
\text { organización. }\end{array}$ \\
\hline 75 & $V_{--}$ & $F_{--}$ & $\begin{array}{l}\text { Cada dirigente es considerado como conocedor de su trabajo y } \\
\text { se le trata como tal. }\end{array}$ \\
\hline 76 & $V_{--}$ & $F_{--}$ & El desempeño de las funciones es correctamente evaluado. \\
\hline 77 & $V_{--}$ & $F_{--}$ & $\begin{array}{l}\text { Los diferentes niveles jerárquicos de la organización colaboran } \\
\text { entre ellos. }\end{array}$ \\
\hline 78 & $V_{--}$ & $F_{--}$ & $\begin{array}{l}\text { Aquí las diferentes áreas de trabajo viven en un conflicto } \\
\text { permanente. }\end{array}$ \\
\hline 79 & $V_{--}$ & $F_{--}$ & Aquí la información está concentrada en unos pocos grupos. \\
\hline 80 & $V_{--}$ & $F_{--}$ & $\begin{array}{l}\text { Los nivele superiores no propician cambios positivos para las } \\
\text { instituciones de base. }\end{array}$ \\
\hline
\end{tabular}

\section{REFERENCI AS BI BLI OGRÁFI CAS}

1. Conferencia Internacional sobre Atención Primaria en Salud. Ginebra: Organización Mundial de la Salud; 1978. Alma-Atá. URSS (6-12 Septiembre de 1978) .

2. Turabian J L. Cuadernos de Medicina de Familia y Comunitaria. España: Díaz de Santos; 1995.

3. Convocatoria de Investigación sobre desarrollo de Recursos Humanos: Gestión de Recursos Humanos, calidad y productividad en salud. Rev Educación Médica y Salud. 1995;29(2):228-35.

4. Lodoño J, Szekely M. Persistent poverty and excess inequality: Latin America 1970- 1995. J Applied Economics. 2000;3(1):93-134.

5. Szekely M. The 1990s in Latin America: another decade of persistent inequality, but with somewhat lower poverty. Washington, D.C.: IDB; 2001.

6. World Health Organizations. Health Systems: principled integrated care. In: WHO, editor. Geneva: WHO;2003. [World Health Report 2003].

7. World Health Organizations. A Global Review of Primary Health Care: Emerging Messages. Geneva: WHO; 2003.

8. World Bank. The Millennium Goals for Health: Rising to the Challenge. Washington, D.C.: IBRD/World Bank; 2004. 
9. Freedman L, Wirth M, Walkman R, Chowdhury M, Rosenfield A. Millennium Project Task Force 4. Chile: Health and Maternal Health; 2004. [Interim Report: Millennium Project].

10. La Salud Pública en Cuba. Hechos y Cifras. Dirección Nacional de Estadística. La Habana: Ministerio de Salud Pública (MINSAP); 1999.

11. World Health Organization. Evolución Macroeconómica y Salud en Cuba. Geneva: WHO; 1998. [Publicación Científica: No.34].

12. Rojo Pérez N. Administración de Recursos Humanos. Generalidades en Salud [CD-ROM]. La Habana: ENSAP;2004.

13. Rojo Pérez N, Alfonso Hernández J. Temas de Organización Científica del Trabajo. La Habana: Instituto de Desarrollo de la Salud; 1988.

14. Aldereguía J. Perfeccionamiento de la Dirección Científica de la Salud Pública Cubana. La Habana: MINSAP; 1985.

15. Sugey Torres. Conceptos de Desarrollo Organizacional [Monografía en Internet]. [citado 4 de Ene 2004]. Disponible en: http://www.monografias.com/trabajos14/desarrollo-organiz/

16. OMS/OPS. Inventario de clima organizacional: Tema y técnicas de desarrollo organizacional. Programa regional de desarrollo de servicios de salud.

Ginebra: OMS; 1998. [No. PSDCG-T-10 Vol. 3 Módulo III. Unidad VI, Pág. 1-7].

17. OMS. Teoría y técnicas de desarrollo organizacional. Guatemala:

OMS; 1990. [Vol. 2. Modulo II. Modelo para el análisis de la organización. Unidad II. Numero PSDCGT.10].

18. OMS. Teoría y técnicas de desarrollo organizacional. Guatemala: OMS; 1990. Vol. 3. Modulo II. Modelo para el análisis de la organización. Unidad V. Numero PSDCGT. 10 .

19. Segredo Pérez AM. Clima organizacional en salud pública. Consideraciones generales. Rev Correo Científico Médico de Holguín. 2004;8(3).

20. Palomino Mariselli RA. Clima Organizacional [sitio en Internet]. [citado 14 Dic 2003]. Disponible en: http://www.sht.com.ar/archivo/temas/clima.htm\#Autor

21. Gonçalves AP. Dimensiones del Clima Organizacional [sitio en Internet]. [citado 14 Dic 2003]. Disponible en: http://www.calidad.org/articles/dec97/artdec97.htm

22. Pérez Masa B. la calidad en los servicios. Medición. Evaluación y mejora. Lecturas seleccionadas. La Habana: Facultad de Salud Pública; 2000.

23. Castell-Florit Serrate P. Glosario Gerencia en salud. La Habana: MINSAP, ENSAP; 2001.

24. Presno Labrador MC. Condiciones organizativas y género en el sistema gerencial del área de salud. Ciudad de la Habana. 1997 [tesis]. La Habana: Facultad de Salud Pública; 1997. 
25. Informe final del sub-comité especial sobre la mujer, la salud y el desarrollo. Washington, D.C.: OMS/OPS; 2000.

26. Anuario Estadístico. Dirección Nacional de Estadística. La Habana: MINSAP; 2003.

27. Pittman $P$, Hartigan $P$. Calidad de la atención y la perspectiva de género ¿Qué sabemos sobre la conexión? Programa. Washington, D.C.: Mujer, Salud y Desarrollo; 1994.

28. Elementos que definen la Gestión del Equipo Básico de Salud. La Habana: ENSAP;2003. [Grupo de investigación ENSAP].

29. López Puig P. Comportamiento del Fondo de Tiempo en Directores de Policlínico. Ciudad de la Habana y La Habana. 2003 [tesis]. La Habana: Escuela Nacional de Salud Pública; 2004.

30. Presno Labrador MC. Condiciones organizativas y género en el sistema municipal de salud. La Habana. 2001 [tesis . La Habana: Escuela Nacional de Salud Pública; 2001.

Recibido: 13 de abril de 2009.

Aprobado: 20 de mayo de 2009.

Alina María Segredo Pérez. Escuela Nacional de Salud Pública. Calle Línea esq. a I. El Vedado 10400. La Habana, Cuba.

* Trabajo para optar por el título de Especialista de II Grado en Medicina General Integral. Escuela Nacional de Salud Pública. La Habana, 2004. 